\title{
Spatial-temporal variation of groundwater and land subsidence evolution in Beijing area
}

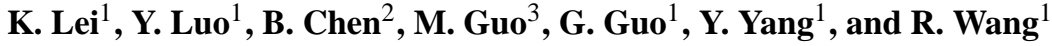 \\ ${ }^{1}$ Beijing Institute of Hydrogeology and Engineering Geology, Beijing 100195, China \\ ${ }^{2}$ College of Resources Environment and Tourism, Capital Normal University, Beijing 100048, China \\ ${ }^{3}$ Beijing Bureau of Geology and Mineral Exploration and Development, Beijing 100195, China
}

Correspondence to: K. Lei (279459260@qq.com)

Published: 12 November 2015

\begin{abstract}
Precipitation is the main recharge source of groundwater in the plain of Beijing, China. Rapid expansion of urbanization has resulted in increased built-up area and decreased amount of effective recharge of precipitation to groundwater, indirectly leading to the long-term over-exploitation of groundwater, and induced regional land subsidence. Based on the combination of meteorological data, groundwater level data, interferometric synthetic aperture radar (InSAR; specifically persistent scatterer interferometry, PSI), geographic information system (GIS) spatial analysis method and rainfall recharge theory, this paper presents a systematic analysis of spatial-temporal variation of groundwater level and land subsidence evolution. Results show that rainfall has been decreasing annually, while the exploitation of groundwater is increasing and the groundwater level is declining, which is has caused the formation and evolution of land subsidence. Seasonal and interannual variations exist in the evolution of land subsidence; the subsidence is uneven in both spatial and temporal distribution. In 2011, at the center of mapped subsidence the subsidence rate was greater than $120 \mathrm{~mm} \mathrm{a}^{-1}$. The results revealed good correlation between the spatial distribution of groundwater level declines and subsidence. The research results show that it is beneficial to measure the evolution of land subsidence to dynamic variations of groundwater levels by combining InSAR or PSI, groundwater-level data, and GIS. This apprpach provides improved information for environmental and hydrogeologic research and a scientific basis for regional land subsidence control.
\end{abstract}

\section{Introduction}

Land subsidence caused by groundwater extraction can be a severe geologic hazard, causing structural damages to infrastructure and environmental damages to land an water resources and can lead to a series of other hazards related to the formation of ground fissures (Galloway et al., 1998; Galloway and Hoffmann, 2007). Some studies attribute the leading cause of regional land subsidence in Beijing China to the overexploitation of groundwater (Chen, 2000). Large-scale and long-term overexploitation of groundwater leads to declining groundwater levels, the deformation(compaction) of clay sediments in the aquifer system, and land subsidence. As the capital of China, Beijing is a metropolis with serious water shortage problems (Lei et al., 2014). More than twothirds of the water supply comes from groundwater. Long term overexploitation of groundwater has led to continuously declining water levels and plays an important role in the formation and development of regional land subsidence (Jia et al., 2007). In the center of mapped subsidence, the cumulative settlement is as much as to $1302 \mathrm{~mm}$; and some areas are still subsiding at a high rate of $100-120 \mathrm{~mm} \mathrm{a}^{-1}$.

This study combines groundwater level data, the PSI technique, GIS spatial analysis methods and rainfall recharge theory to analyze spatial-temporal variations of the groundwater system and evolution of land subsidence in the Beijing plain area, China. The study also analyzes the spatial and temporal variability of rainfall groundwater recharge derived from precipitation. The relation between groundwater-level variations and the evolution of land subsidence is demonstrated. 


\section{Study area}

Beijing $\left(39^{\circ} 28^{\prime}-41^{\circ} 05^{\prime} \mathrm{N}, 115^{\circ} 25^{\prime}-117^{\circ} 35^{\prime} \mathrm{E}\right)$, located in the north of China, is divided into three parts: northern mountains, western mountains and south-eastern plains. The climate in Beijing is characterized by uneven seasonal precipitation, with over $70 \%$ of the annual precipitation distributed between June and August. During recent decades, rainfall has been declining continuously attributed in part to the impact of global climate change; the average annual rainfall was $479.49 \mathrm{~mm}$, equivalent to $84.2 \%$ of the average annual rainfall for the period of record.

\section{Methodologies}

\subsection{Estimation of rainfall recharge to ground water}

Kriging was employed to spatially interpolate observed precipitation data from 20 national weather stations in Beijing. The principle of Kriging interpolation is based on:

$Z_{0}^{*}=\sum_{i=1}^{n} \lambda_{0}^{i} Z_{i}$

where, $Z_{0}^{*}$ is Kriging interpolation values; $Z_{i}$ is observations of the position $\chi_{i}(i=1,2, \ldots, n)$. Groundwater recharge from rainfall was estimated by using

$Q=10^{3} a \cdot X \cdot F$,

where $Q$ is rainfall infiltration recharge $\left(\mathrm{m}^{3}\right) ; a$ is the infiltration coefficient; $X$ is average annual rainfall $(\mathrm{mm})$; and $F$ is infiltration area.

Landsat TM images of three periods (2000, 2006, 2009) covering the Beijing area were used to extract spatialtemporal information on the expansion of built-up areas by the supervised classification method. Then, loss in rainfall recharge(precipitation minus groundwater recharge derived from infiltration of precipitation) was calculated by GIS raster calculation using groundwater recharge from rainfall and the built-up area.

\subsection{Deformation monitoring using PSI}

Persistent scatterers (PSI) can effectively reduce the spatial and temporal decorrelation effects and reduce the error component caused by atmospheric delay versus traditional InSAR. Through error corrections on atmospheric, orbit and digital elevation model (DEM) phase components, accurate deformation rates can be extracted (Ferretti et al., 2001; Hooper, et al. 2004). The PSI method was used in this study:

$\phi_{x, i}=\phi_{\mathrm{def}, x, i}+\phi_{\varepsilon, x, i}+\phi_{\mathrm{atm}, x, i}+\phi_{\mathrm{orb}, x, i}+\phi_{n, x, i}$,

where, $\Phi_{\text {def }, x, j}$ is the deformation phase of viewing direction; $\Phi_{\varepsilon, x, j}$ is the residual topographic phase introduced by

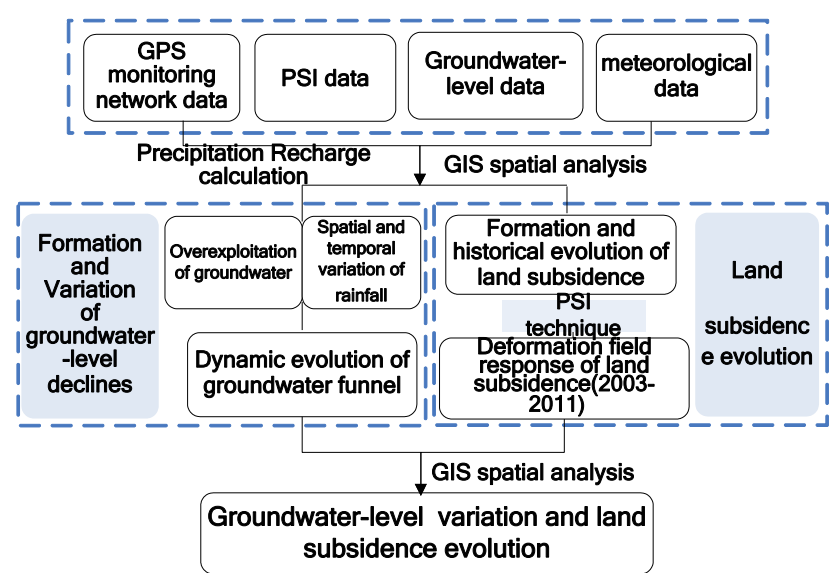

Figure 1. Framework diagram of the comprehensive analysis method.

errors in the external DEM; $\Phi_{\mathrm{atm}, x, j}$ is the phase difference of atmospheric delays between two satellite transits; $\Phi_{\mathrm{orb}, x, j}$ is the phase component of orbit error; $\Phi_{\mathrm{n}, x, j}$ is the noise component; $x, j$ is row number, line number for pixels.

\subsection{Comprehensive analysis method}

Combined with groundwater level data, meteorological data, PSI data and GIS were used to analyze groundwater level variations and the evolution land subsidence. The spatial and temporal variability of rainfall and its recharge to groundwater, is described in terms of the spatial and temporal correlations of groundwater level declines and land subsidence (Fig. 1).

\section{Results and analysis}

\subsection{Spatial and temporal variability of precipitation and recharge to groundwater}

\subsubsection{Spatial and temporal variability of rainfall}

Meteorological data was compiled from 20 weather stations for six typical periods $(1997,2000,2003,2006,2009$ and 2011) to develop time series contour maps of rainfall using the Kriging method (geostatistical tool of ArcGIS) (Fig. 2). The results show the spatial and temporal variation of rainfall in Beijing. In 1997, the rainfall was mainly concentrated in the northeast region and the average precipitation was $438 \mathrm{~mm}$. In 2003, the rainfall was mainly concentrated in Yan-Qing and Fang-Shan where the average precipitation was $457 \mathrm{~mm}$. In 2006, the rainfall was mainly concentrated in Ping-Gu and the average precipitation was $491 \mathrm{~mm}$. In 20092011, there was a significant difference of precipitation between eastern areas and western areas. The precipitation in the central and eastern area was greater than $572 \mathrm{~mm}$ and distributed evenly. 

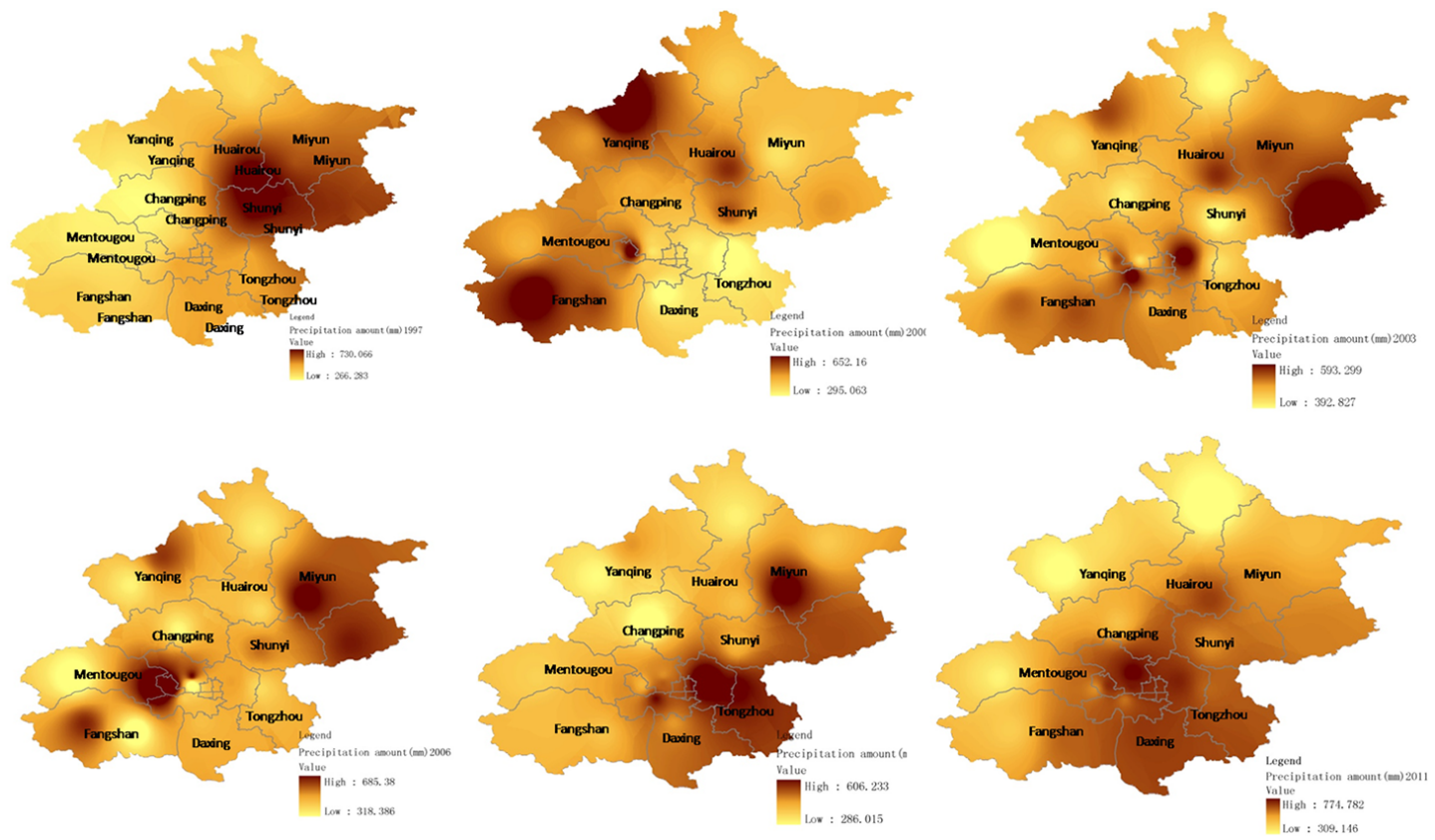

Figure 2. Spatial and temporal variability of rainfall (1997-2011).
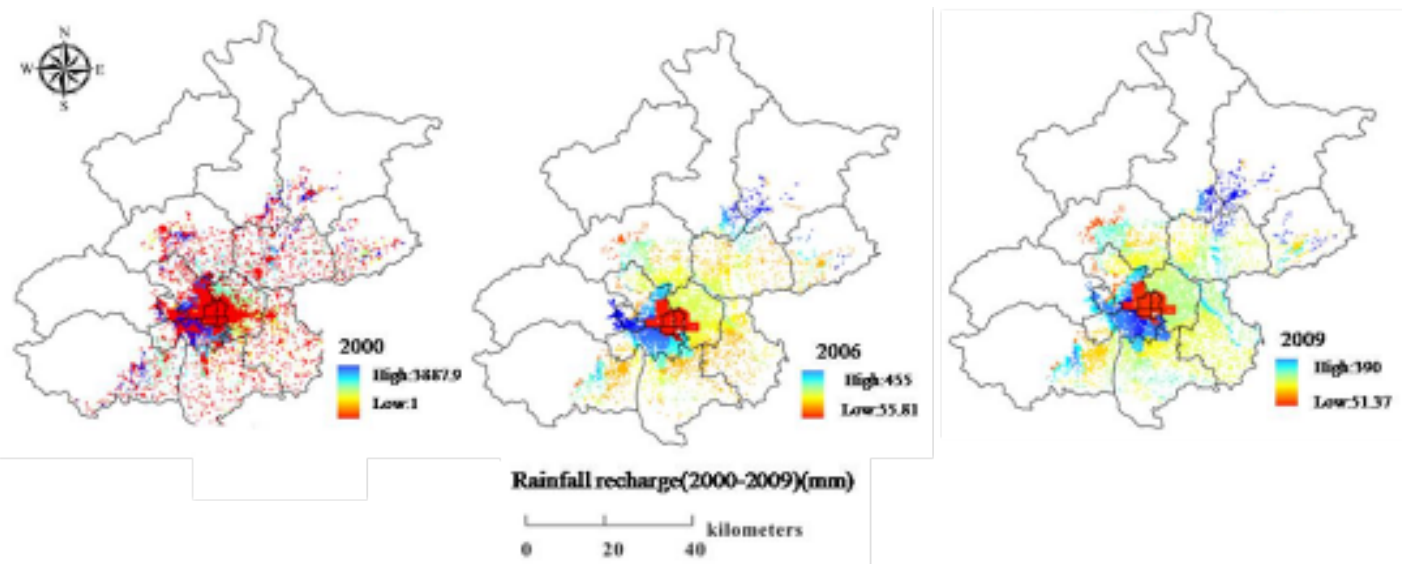

Figure 3. Spatial-temporal distribution of effective recharge to groundwater from rainfall (2000-2009).

\subsubsection{Groundwater recharge from rainfall}

With the decline of precipitation, groundwater recharge is decreasing considerably due to the growth of impervious areas, which result from the urbanization of Beijing.

Land use derived from Landsat TM images of three periods $(2000,2006,2009)$ showed in Fig. 3 that the built-up area was $2246.94 \mathrm{~km}^{2}$ in 2000 , growing to $2344.97 \mathrm{~km}^{2}$ in 2006 , and growing further to $2767.22 \mathrm{~km}^{2}$ in 2009 - a more than $20 \%$ increase since 2000. With the expansion of impervious area (built-up area), and reduced groundwater recharge from rainfall led to the over-exploitation of groundwater.

Recharge from rainfall to the groundwater system was obtained by using GIS raster calculations and statistical analysis of groundwater recharge from rainfall accounting for the built-up area. In 2000, effective rainfall recharge was $18.81 \times 10^{8} \mathrm{~m}^{3}$, accounting for $48 \%$ of the total annual rainfall $\left(39.41 \times 10^{8} \mathrm{~m}^{3}\right)$, residual rainfall not contributing to groundwater recharge (loss) was $52 \%$ in $2000,61 \%$ in 2006, and $62 \%$ in 2009 . The results suggest that with the increasing built-up area, the loss amount of rainfall recharge to groundwater was increasing. Two-thirds of the Beijing water supply is from groundwater. With urban area expansion, water requirements and groundwater demand and exploitation are increasing annually. Thus, groundwater levels have been declining, which leads to formation and evolution of subsidence. 

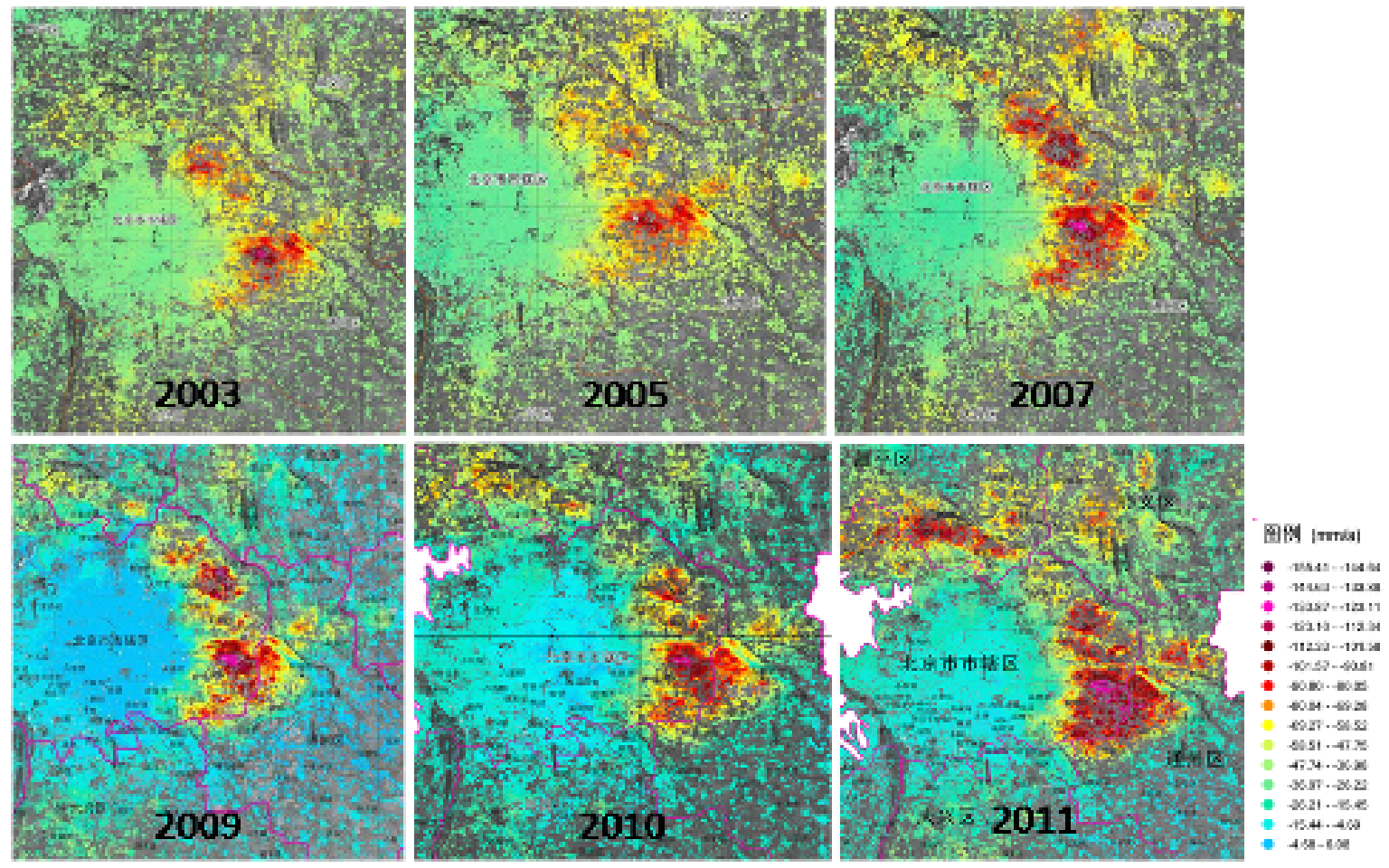

Figure 4. Land subsidence mapped using PSI technique (2003-2011).

\subsection{Land subsidence evolution to resulting from variation of groundwater levels}

\subsubsection{Spatial-temporal distributions of land subsidence (2003-2011)}

The time series land subsidence information was acquired using the InSAR PSI technique and the result was validated by leveling survey measurements.

According to the time-series PSI results, the subsidence expanded steadily during 2003-2011. In 2011, the cenrer of subsidence was subsiding $120 \mathrm{~mm} \mathrm{a}^{-1}$, and about $1087 \mathrm{~km}^{2}$, mainly in the Changping, Shunyi, Chaoyang and Tongzhou Districts was subsiding more than $30 \mathrm{mma}^{-1}$ (Fig. 4).

\subsubsection{Relationship between groundwater level variation and land subsidence evolution}

The correlation between groundwater level variation and land subsidence evolution was analyzed by comparing groundwater level contoursfor select years during 20032011, with the average settlement rate obtained by the PSI technique during 2003-2011 (Fig. 5). Greater settlement rates are fairly well correlated with areas of greater groundwater-level declines-as indicated by the depth to water-level contours, mainly distributed in Tianzhu of Shunyi District, Chaoyang District and north-western Tongzhou District. The groundwater level was declining continuously with an average rate of $2.18 \mathrm{ma}^{-1}$ and a maximum rate of $3.82 \mathrm{ma}^{-1}$ in the area of maximum regional groundwaterlevel declines.

\section{Conclusions}

1. The paper analyzed the spatial and temporal variability of rainfall and its recharge to groundwater during 2000-2009. With declining precipitation, groundwater recharge was decreasing heavily due to reduced precipitation and to the growth of impervious areas. Meanwhile, water requirements and groundwater exploitation were increasing annually. Groundwater level has been declining, which has led to formation and evolution of a regional cone of depression in the groundwater system and land subsidence.

2. The land subsidence (during 2003-2011) was measured and mapped using PSI. In 2011, the settlement rate at the center of subsidence was larger than $120 \mathrm{mma}^{-1}$, $1087 \mathrm{~km}^{2}$ was subsiding at a rate larger than $30 \mathrm{~mm} \mathrm{a}^{-1}$.

3. From the comparison between variation of groundwater levels and subsidence, the results suggested that the spatial distribution of groundwater-level declines was fairly well correlated with the mapped subsidence, but not entirely. 

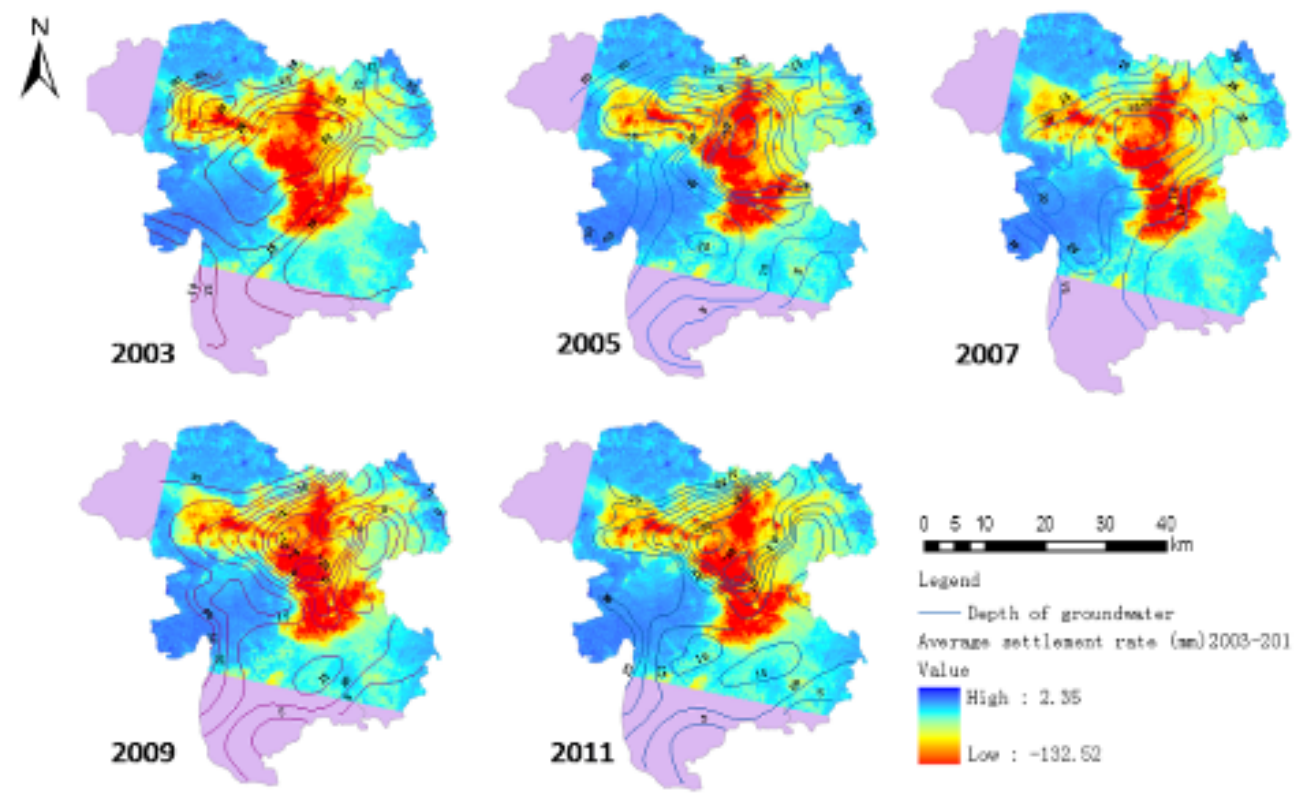

Figure 5. Groundwater contours (depth to water) and land subsidence.

Acknowledgements. This research was funded by the Beijing Municipal Science and Technology Project (Z131100005613022).

\section{References}

Chen, C. X.: Thinking on Land Subsidence Caused By Groundwater Exploitation, Hydrogeology and Engineering Geology, 27, 45-60, 2000.

Ferretti, A., Prati, C., and Rocca, F.: Permanent scatterers in SAR interferometry, IEEE T. Geosci. Remote, 39, 8-20, 2001.

Galloway, D. L. and Hoffmann, J.: The application of satellite differential SAR interferometry-derived ground displacements in hydrogeology, Hydrogeol. J., 15, 133-154, 2007.

Galloway, D. L., Hudnut, K. W., Ingebritsen, S. E., Phillips, S. P., Peltzer, G., Rogez, F., and Rosen, P. A.: Detection of aquifersystem compaction and land subsidence using interferometric synthetic aperture radar, Antelope Valley, Mojave Desert, California, Water Resour. Res., 34, 2573-2585, 1998.
Hooper, A., Zebker, H., Segall, P., and Kampes, B.: A New Method for Measuring Information on Volcanoes and Other Natural Terrains Using InSAR Persistent Scatterers, Geophys. Res. Lett., 31, $1-5,2004$.

Jia, S. M., Wang, H. G., Zhao, S. S., and Luo, Y.: A Tentative Study of the Mechanism of Land Subsidence in Beijing, City Geology, 2, 20-26, 2007.

Lei, K. C., Chen, B. B., Jia, S. M., Wang, S. F., and Luo, Y.: Formation and Genetic Mechanism of Land Subsidence Based on PS-InSAR Technology in Beijing, Spectrosc. Spect. Anal., 34, 2185-2189, 2014 